\title{
Resistance to Fusarium head blight in oats based on analyses of multiple field and greenhouse studies
}

\author{
Juho Hautsalo $(\mathbb{D}$ - Lauri Jauhiainen • Asko Hannukkala • Outi Manninen • Merja Veteläinen • Leena Pietilä • \\ Kirsi Peltoniemi • Marja Jalli
}

Accepted: 11 June 2020 /Published online: 16 July 2020

(C) The Author(s) 2020

\begin{abstract}
Fusarium head blight (FHB) and the mycotoxins produced by its causal agents in oats (Avena sativa L.) have become a growing problem in northern countries over the last decades. The development of resistant cultivars would offer a highly needed and economical solution to the problem. To tackle the high genotype $\times$ environment interaction of FHB, a combined analysis was carried out on eight greenhouse and 13 field experiments inoculated with DON-producing $\mathrm{Fu}$ sarium species. Our data included 406 oat genotypes consisting of Nordic cultivars, breeding lines and potentially resistant gene bank accessions. High variation in the DON accumulation estimates in the material shows that the selection of genotypes with better resistance would be valuable. The greenhouse and field studies resulted in significantly different oat genotype susceptibility rankings for both DON and Fusarium infected kernels. The results obtained from the field experiments have more practical relevance for farmers and breeders for the identification of DON resistant cultivars than
\end{abstract}

Asko Hannukkala passed away on 10 May 2020.

Electronic supplementary material The online version of this article (https://doi.org/10.1007/s10658-020-02039-0) contains supplementary material, which is available to authorized users.

J. Hautsalo $(\bowtie)$

Natural Resources Institute Finland, Survontie 9A,

FI-40500 Jyväskylä, Finland

e-mail: juho.hautsalo@luke.fi

J. Hautsalo · A. Hannukkala

Department of Agricultural Sciences, FI-00014 University of

Helsinki, Helsinki, Finland greenhouse screenings. Days to maturity and the plant height of the genotypes both significantly affected the Fusarium infections and DON in the field. The relationship between Fusarium infected kernels, DONand germination capacity provide an insight into the composition of genotypes with resistance. The core set of 30 oat genotypes, which were phenotyped in several experiments, provides valuable examples of both highly susceptible and moderately resistant oat genotypes.

Keywords Fusarium resistance $\cdot$ Oats $\cdot$ DON . Phenotyping · Resistance components · Meta-analysis · Mycotoxins $\cdot$ Cereals

\section{Introduction}

Cultivated oats (Avena sativa L.) are an important export crop for northern countries such as Finland, Sweden and Canada (FAOSTAT 2016). Oats are used both

L. Jauhiainen · A. Hannukkala $\cdot$ M. Jalli

Natural Resources Institute Finland, Tietotie 4, FI-31600,

Jokioinen, Finland

O. Manninen · M. Veteläinen · L. Pietilä $\cdot$ K. Peltoniemi Boreal Plant Breeding Ltd., Myllytie 10, FI-31600, Jokioinen, Finland 
for food and animal feed and are considered a healthy cereal due to a number of nutritional compounds including $\beta$-glucan which has been confirmed to lower blood cholesterol and reduce the risk of heart disease (EFSA 2009 and 2011). The health benefits of oats have contributed to the development of a range of new oat products. In addition, Nordic oats are branded for their high quality. Unfortunately oats are also susceptible to Fusarium head blight (FHB), a disease which in recent years has reduced yields and seed germination and has led to the severe accumulation of the mycotoxin deoxynivalenol (DON) in all oat production areas (Hietaniemi 2016, Tekle et al. 2013, Tekauz et al. 2004).

The main causal agent of FHB, Fusarium graminearum Schwabe sensu stricto, has recently become the most important Fusarium species affecting cereals in Nordic European countries (Hofgaard et al. 2017, Hietaniemi et al. 2016, Fredlund et al. 2013) and it is the most prevalent species associated with the disease in Canada (Tekauz et al. 2004). DON is produced by both $F$. graminearum and F. culmorum (Wm. G. Sm.) which are favoured by different weather conditions. $F$. culmorum usually infects cereals in wet and cool conditions ( $\mathrm{Xu}$ et al. 2008), whereas $F$. graminearum infections occur in warm, rainy and humid conditions during flowering (Hjelkrem et al. 2017).

Resistance breeding programmes have already generated some oat cultivars with considerably lower mycotoxin accumulation when they are compared to other cultivars (Tekle et al. 2018, Yan et al. 2010). In addition, several potential resistance sources from cultivars and landraces have been identified based on resistance screening experiments (Tekle et al. 2018, Bjørnstad et al. 2017, Loskutov et al. 2016, Yan et al. 2010). The resistance in oats has a quantitative nature (He et al. 2013, Bjørnstad et al. 2017) and the genes behind the resistance are still unknown. Resistance against FHB in cereals is commonly divided into at least five separate components of resistance. Resistance against initial infection and the spreading of infection (Schroeder and Christensen 1963) are known as type I and II resistance, respectively, whereas mycotoxin resistance is known as type III resistance (Miller et al. 1985). Resistance against kernel infections is called type IV resistance and tolerance is referred to as type $\mathrm{V}$ resistance (Mesterházy 1995, Mesterházy et al. 1999). However, the numbering of the types III-V is somewhat inconsistent in the literature (e.g. Mesterházy et al. 1999 vs. Mesterházy 2002) and therefore we refer to these three as: resistance to kernel infection, tolerance, and resistance to mycotoxin accumulation, instead of using the abbreviations. In addition, there are many morphological features, such as plant height (Mesterházy 1995), which may act as disease escape mechanisms and thus complicate resistance evaluation.

Gathering enough phenotypic information to draw reliable conclusions on the Fusarium resistance in oats requires a toolbox of different analyses which measure different resistance components. An artificial inoculation system is needed to ensure sufficient infection and repetition reduces the high environmental variation (Hautsalo et al. 2018). In natural infections the differences between oat genotypes are often too small to be reliably distinguished from each other due to the low or unevenly distributed infection pressure. Moreover, the mycotoxin accumulation is also dependent on particular species causing the FHB. Natural infections are often highly dependent on factors such as the weather (Hjelkrem et al. 2017), the previous crop (Dill-Macky and Jones 2000) and the tillage (Kaukoranta et al. 2019). In wheat, the disease severity can be used as a parameter for selection (Buerstmayr and Lemmens 2015), but this is not seen as a reliable method for oats and therefore more analyses are needed from harvested samples (Tekle et al. 2018). This all makes the breeding of Fusarium resistant oat cultivars a time-consuming and expensive effort. For example Tekle (2018) et al. achieved reliable cultivar resistance rankings, relying on DON accumulations and germination capacities from a minimum of 4 years of spawn inoculated nursery experiments, whereas Xue et al. (2015) used inoculated growth chamber experiments and they were able to separate Canadian oat genotypes concerning their resistance to FHB based on DON and infected spikelets.

Controlled environments and artificial inoculations are often used for disease resistance research purposes (Afanasenko et al. 2009). However, for large-scale screening purposes, a controlled environment is not always economically or practicable. The results from experiments carried out in controlled environment may not always apply in field conditions. The consistency of results between greenhouse and field trials has varied in experiments studying FHB resistance in transgenic wheat lines (Anand et al. 2003, Mackintosh et al. 2007) as well as in studies of biological control agents against FHB in wheat (Schisler et al. 2002). Greenhouses are generally considered to be the most reliable environment for the assessment of the resistance against 
the spread of infection for wheat, while field studies are seen to provide more comprehensive estimates of the overall FHB resistance.

Further studies are needed to better understand how to utilise greenhouse and field research facilities for phenotyping the resistance against FHB in the most efficient way. With special focus on determining the state of FHB resistance in Finnish oats, this study attempts to carry out a combined analysis of several artificially inoculated greenhouse and field experiments assessing FHB resistance in oat material (Nordic cultivars, Finnish breeding material and various gene bank accessions that have shown some resistance in earlier studies (Gagkaeva et al. 2013)). The aim with the combined analyses is to gain a more comprehensive estimate of the FBH resistance. In addition, this study highlights the possible differences between greenhouse and field environments concerning the resistance rankings and describes the interaction between resistance components (DON accumulation, germination capacity and Fusarium infected kernels) and typical escape mechanisms (plant height, maturation time)..

\section{Material and methods}

\section{Data description}

The data were collected from eight greenhouse (Table 1) and 13 field FHB resistance screening experiments (Table 2) conducted in Southern (Jokioinen, 60 $48^{\prime}$ $55^{\prime \prime} \mathrm{N} 23^{\circ} 28^{\prime} 35^{\prime \prime} \mathrm{E}$ ) and Central Finland (Laukaa, $\left.62^{\circ} 19^{\prime} 22^{\prime \prime} \mathrm{N} 25^{\circ} 59^{\prime} 05^{\prime \prime} \mathrm{E}\right)$ by the Natural Resources Institute Finland (Luke). These experiments were designed for various projects to test potential FHB resistance sources in oats, as well as to develop phenotyping methods for FHB resistance screening. The oat genotypes studied in these greenhouse and field experiments included 348 oat breeding lines from Boreal Plant Breeding Ltd., 40 north European oat cultivars and 16 gene bank accessions from the N. I. Vavilov Research Institute of Plant Industry (VIR).

Most of the breeding lines were included only in a few experiments (on average three experiments), but some oat genotypes ('BOR31', 'Belinda', 'Akseli') that were used as checks were represented in 14,16 and 18 experiments, respectively. The 'Akseli' and 'BOR31' genotypes were included as check cultivars in every greenhouse experiment since 2013 and the 'Belinda' genotype was included in all field experiments. The 'BOR31' genotype is a rejected variety that has never been entered the market and the breeder no longer maintains the seeds. A core set of 30 oat genotypes containing cultivars, breeding lines and gene bank material were selected to be studied more carefully in 2017 in the field because these genotypes had DON accumulation and germination data from a minimum of three separate field experiments. The exact number of analyses behind each core genotype's estimates is provided in the supplementary material (S1).

Greenhouse experiments

The greenhouse experiment data consisted of eight experiments (Table 1) that were carried out between 2012 and 2016 in greenhouses at the Natural Resources Institute Finland (Luke) and Boreal Plant Breeding Ltd., Jokioinen, Finland. The experimental design as well as the number of replicates varied in the experiments (Table 1) according to the purpose of the trial. The spray inoculation protocol for the greenhouse experiments was developed by testing different fungal isolates or inoculum concentrations for which a sufficient number of replicates were needed. These were all added as replicates for the oat genotypes.

In the greenhouse trials, the temperature was set at 18 $\pm 2 \mathrm{C}$ during the day and $15 \pm 2 \mathrm{C}$ during the night. Five plants per pot were grown in a fertilized medium containing peat and sand. After spray inoculations, the temperature was raised to $20 \mathrm{C}$ during the day and $18 \mathrm{C}$ at night and the light intensity was kept above $200 \mathrm{~W} / \mathrm{m}^{2}$ $16 \mathrm{~h}$ per day. Oats were spray inoculated during the main stem anthesis (GS 65, Zadoks 1974) with a $2 \mathrm{ml}$ per plant of a suspension containing Finnish $F$. culmorum isolates 05018 (for the first five experiments, Table 1) or 05015 (for the last three experiments, Table 1) and with $F$. graminearum isolate 05011 (for the last four experiments, Table 1). The concentration of the inoculum varied between 80,000 and 500,000 spores per $\mathrm{ml}$ from one experiment to another. During the inoculation, mist irrigation was applied for $2 \mathrm{~h}$ before and $6 \mathrm{~h}$ after the inoculation. The main stems (5 panicles per pot) were harvested at GS92 (Zadoks 1974).

Field experiments

The field experiments were inoculated by spraying them once during anthesis (GS 65) with F. culmorum isolate 
Table 1 The greenhouse experiments included in the study. The experiments are categorized by year. Numbers of replications per experiment (Reps) and oat genotypes (Oats) are provided. For each experiment the available range and number of samples analysed for DON accumulation (DON, $\mathrm{n}=\mathrm{xx}$ ) and Fusarium infected kernels (FIK, $\mathrm{n}=\mathrm{xx}$ ) are shown together with the difference between our two check genotypes (moderately resistant
Akseli and susceptible BOR31). The number of samples in the analyses may differ for the number of genotypes. This is because some genotypes have been used as check cultivars or the yield was insufficient for some of the analyses. The last column shows the Spearman's rank correlation (r) between DON and FIK, while n.s. indicates not significant and $* * *$ is equal to $P<0.001$

\begin{tabular}{lrllllllll}
\hline Year & Oats & Reps $\begin{array}{l}\text { Average (and range) } \\
\text { of DON } \mu \mathrm{g} / \mathrm{kg}\end{array}$ & $\begin{array}{l}\text { DON } \\
(\mathrm{n}=\mathrm{xx})\end{array}$ & $\begin{array}{l}\text { Difference between } \\
\text { checks, } \mu \mathrm{g} / \mathrm{kg}\end{array}$ & $\begin{array}{l}\text { Average (and } \\
\text { range) of FIK \% }\end{array}$ & $\begin{array}{l}\text { FIK } \\
(\mathrm{n}=\mathrm{xx})\end{array}$ & $\begin{array}{l}\text { Difference between } \\
\text { checks, \%-units }\end{array}$ & $\begin{array}{l}\mathrm{r}(\mathrm{DON}, \\
\text { FIK) }\end{array}$ \\
\hline 2012 & 8 & 6 & $1646(686-4199)$ & 8 & - & $71(13-100)$ & 48 & - & n.s. \\
2013 & 190 & 3 & - & - & - & $89(6-100)$ & 607 & 13 & - \\
& 190 & 3 & - & - & - & $98(60-100)$ & 608 & 17 & - \\
2014 & 39 & 4 & - & - & - & $55(2-100)$ & 160 & 10 & - \\
2015 & 7 & 16 & $10,604(500-45,100)$ & 112 & 6219 & $89(54-100)$ & 112 & 18 & $0.49^{* * *}$ \\
& 10 & 24 & $9606(19-60,000)$ & 185 & 34,283 & $66(2-100)$ & 164 & - & $0.68^{* * *}$ \\
2016 & 21 & 8 & $7662(20-60,288)$ & 163 & 19,850 & $67(6-100)$ & 157 & 74 & $0.75^{* * *}$ \\
Total & 234 & 8 & $7614(30-70,000)$ & 202 & 28,832 & $58(1-100)$ & 243 & 56 & $0.72^{* * * *}$ \\
\hline
\end{tabular}

05018 similarly to the greenhouse inoculations in 2012 , 2013 and 2014. Since 2015, a spawn inoculation method (Tekle et al. 2018, Skinnes et al. 2010) was applied with an isolate mixture of five $F$. graminearum isolates $(12,007,12,010,05011,05039$ and 06249) which have been isolated from Finnish cereals. The plots in the field experiments were either small hill plots containing 20 seeds per one oat genotype, or row plots containing six metre-long rows of which one oat genotype represented two to three rows per 0.5 to $0.75 \mathrm{~m}^{2}$. All the field experiments had from one to four replicates. For the spawn inoculated experiments, a total of $1 \mathrm{~h}$ of irrigation was applied daily during the evening hours between 7 PM and 10 PM from anthesis to yellow maturity (GS 87) from 2015 to 2017. The application of fertiliser and herbicides was done according to local needs. Fungicides were not applied in these experiments. From the hill plots only the main stems were harvested, but from the experiments in rows all the matured panicles were harvested.

Analysed traits

The purpose of each experiment determined which traits were analysed. The percentage of Fusarium infected kernels (FIK) was noted for all of the experimental units $(n=4661)$. The DON accumulation (DON) was recorded for $50.4 \%$ of the total number of observations and the germination capacity was observed from $58.8 \%$ of the harvested samples. Before the analyses, the yield was threshed to remove most of the small and empty grains. Additionally, broken or green grains were removed for the FIK or GC analyses, but not from DON samples.

The FIK was estimated by plating 100 grains/ replicate on a selective PCNB (pentachloronitrobenzene (Nash and Snyder medium, Nelson et al. 1983)) medium favouring Fusarium growth instead other fungi or bacteria. The FIK was determined either after 3 days or 1 week of incubation at $23{ }^{\circ} \mathrm{C}$, when the variation in infection rates between genotypes was the most pronounced. DON-mycotoxin contamination was analysed from milled grain samples using an ELISA kit (R5906 Ridascreen DON 96 test, R-Biopharm, Darmstadt, Germany). A commercial reference sample for DON, TRD100 (R-Biopharm, Darmstadt, Germany), was used to check that our DON analyses gave consistent results. A typical yield for two row plots was around $200 \mathrm{~g}$ from which a subsample of $1 / 2$ of the yield was milled for a DON analysis. If the yield was lower than $100 \mathrm{~g}$, the entire sample was milled for analysis. The germination capacity (GC) was determined with a standard paper test from a sample of 100 grains/replicate (ISTA 2006). Harvested yields were subsampled for analyses either by hand (greenhouse) or by using a sample divider.

The impact of DON on the germination of the oat genotypes was analysed by dividing the experiments into two groups based on a low and high DON accumulation. Group 1 included three experiments, 455 observations and it had an average DON of 


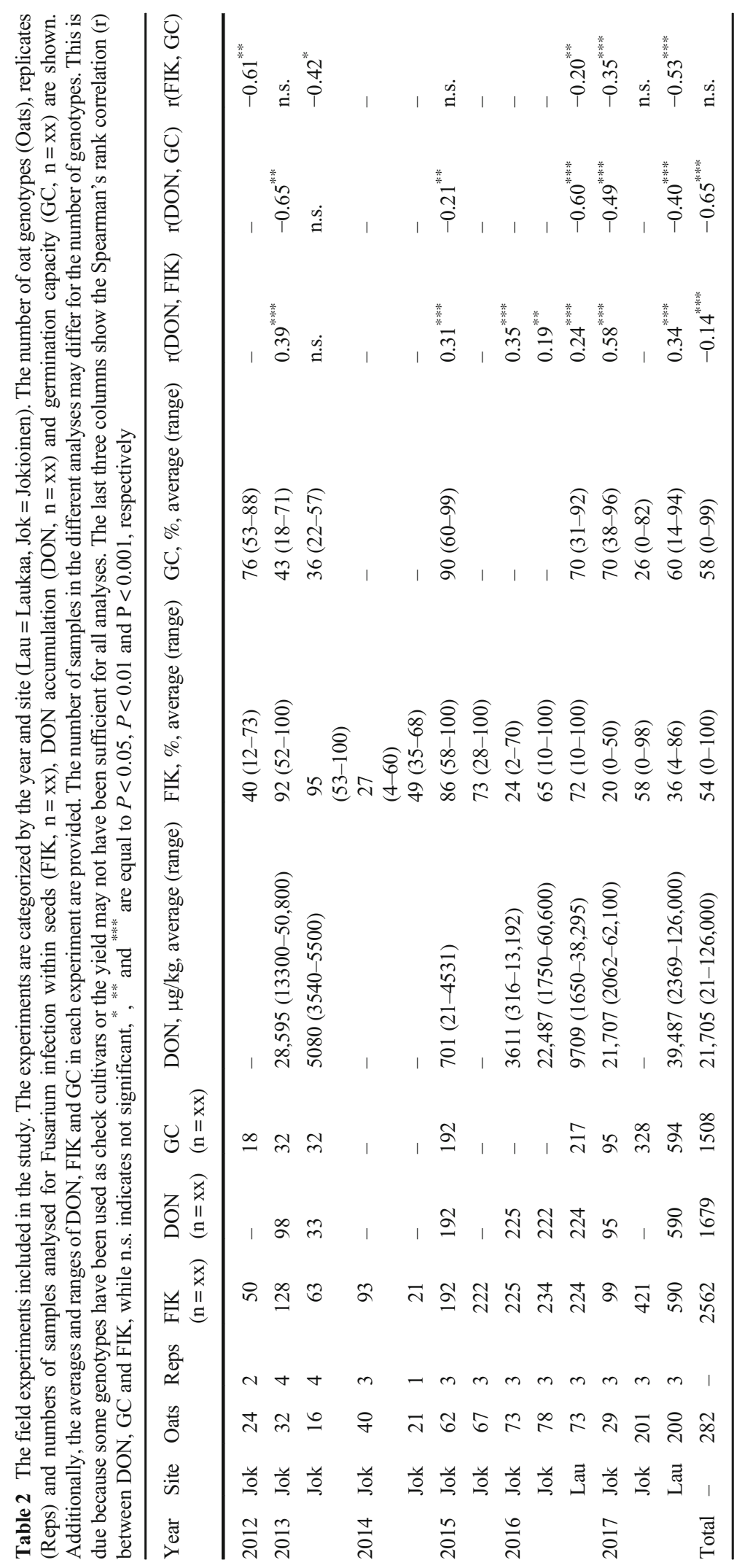


$7525 \mu \mathrm{g} / \mathrm{kg}$ and a germination rate of $60.6 \%$. Group 2 included three experiments, 783 observations and it had an average DON content and germination rate of $33,185 \mu \mathrm{g} / \mathrm{kg}$ and $66.3 \%$, respectively.

Data from breeder's experiments (Boreal Plant Breeding Ltd.) between 2008 and 2017 on the maturity and plant height $(\mathrm{PH})$ were added to the meta-analysis data set. We added data based on at least five experiments for 200 oat genotypes. The maturity was rated from 1 to 5,1 being early to mature and 5 being late maturing. In terms of the growing degree days required for the genotypes to mature, classes 1 and 2 required from 910 to 960 degree days, while class 3 needed from 960 to 990 degree days, class 4 took between 990 and 1020 degree days and class five required more than 1020 degree days. The heights of the oat genotypes were classified into three groups. Group 1 included the shortest and group 3 included the tallest genotypes. For comparison, we have included accurate measurements of the days to heading (DTH), days to maturity (DTM) and plant height $(\mathrm{PH}, \mathrm{cm})$ from the soil surface to panicle tip) for the core data set. The DTH was measured at the Laukaa site in 2016 and 2017. The DTM was measured for two separate experiments at the Jokioinen site in 2017 and PH was measured for the Laukaa experiment in 2016 and 2017 and from one experiment at the Jokioinen site in 2017.

\section{Statistical methods}

Best linear unbiased estimators (BLUEs) for all genotypes were estimated using the following statistical model based on the data collected:

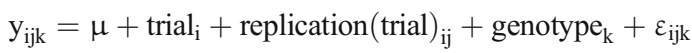

where $\mu$ is the intercept, trial ${ }_{i}$ is the random effect of the ith trial $(i=1, \ldots, 21$; eight greenhouse and 13 field FHB resistance screening experiments), replication(trial $)_{\mathrm{ij}}$ is the random effect of the $j$ th replication $(j=1, \ldots, 4)$ within the ith trial, genotype $e_{\mathrm{k}}$ is the fixed effect of the kth genotype and $\varepsilon_{\mathrm{ijk}}$ is the residual. The model was applied to analyses in which only a part of the trials (either greenhouse trials or field trials) were included. This model and the estimated means for the genotypes were used when comparing two or more classes of genotypes mutually, e.g. genotypes for different $\mathrm{PH}$ or maturity categories.

When comparing how the responses of the genotypes varied between environments (i.e. between the greenhouse and field FHB resistance screening experiments), two fixed effects were added to the original statistical model. These were environment 1 and genotype-by-environment $\mathrm{k}_{\mathrm{k}}$ interaction effects $(1=1,2)$. In addition, the random effect of the trial was nested in the environment in the new model.

Unbalanced data, in which not all of the genotypes are present in all of the trials, would lead to biased estimates if a simple regression model were to be applied. Therefore a model that includes several sources of variation is needed. Searle (1987) showed that genotype effects can be estimated in any well-defined linear mixed model analysis if the turnover of genotypes tested is less than $20 \%$. In fact a higher turnover of genotypes is allowed if some control cultivars are included in almost all the trials. Our data were not optimal, but most of the differences between genotypes can be estimated without bias using a mixed model.

All the models were fitted using SAS-software with the MIXED-procedure and REML estimation method. Assumptions about the normal distribution and homogeneity of the error variance were checked using boxplots of residuals and a scatter plot of residual and fitted values. The DON was normally distributed after a $\log _{\mathrm{e}^{-}}$ transformation. However, all the estimates and their standard errors were transformed back to the original scale for the presentation of the results. A correlation analysis was performed using the SAS/CORR-procedure. Relationships between variables were not typically linear, as a Pearson's correlation coefficient assumes, and therefore a Spearman's rank correlation coefficient was used to test statistical dependence.

In a statistical power analysis the magnitude of the least significant difference between two genotypes was calculated as a function of the sample size required. The statistical significance criterion was set to $5 \%$ and the statistical power was set to $50 \%$. The sampling error was calculated separately for the field and greenhouse trials. The sampling error described how much the difference between any two genotypes varied between trials and not the within-trial variation. After that the magnitude of the effects (i.e. the least significant difference) was calculated as a function of the sample size. Calculations were made using the SAS-software. DON was normally distributed after a $\log _{\mathrm{e}}$ transformation and therefore a power analysis of the DON was carried out on a $\log _{e}$ scale, in which DON $4000 \mu \mathrm{g} / \mathrm{kg}$ was used as a reference level $\left(\log _{\mathrm{e}} 4000=8.29\right)$. However, all the presented results were transformed back to the original scale. 

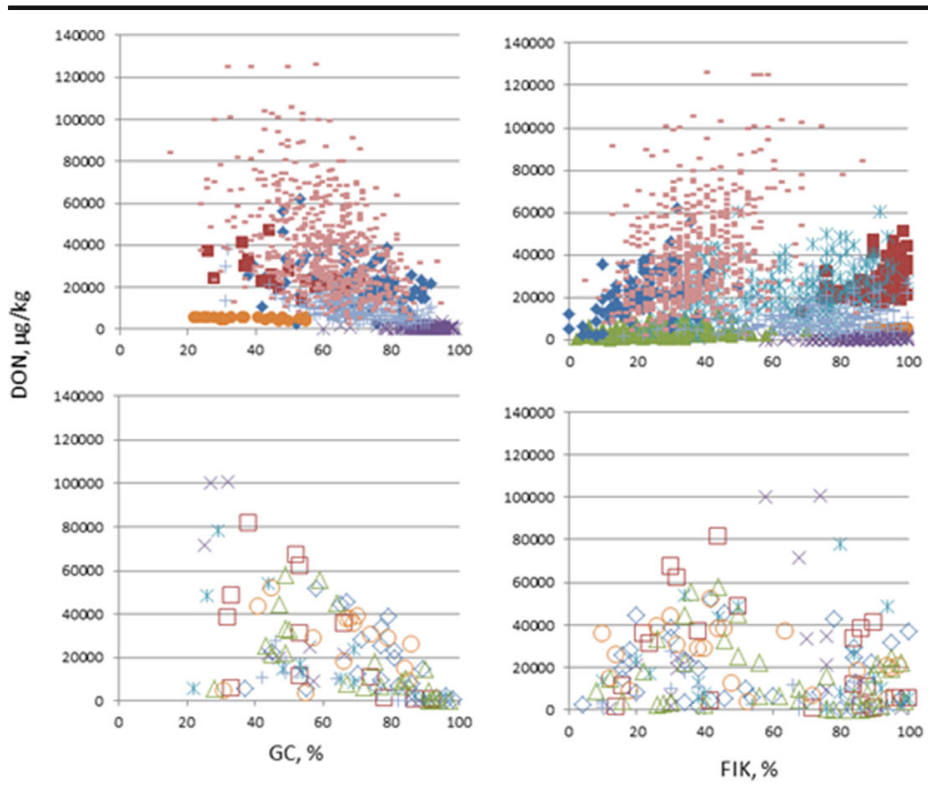

E 2013 Jokioinen I - 2013 lokioinen II $\times 2015$ Jokioinen $\triangle 2016$ Jokioinen I ×.2016 Jokioinen II + 2016 Lavikas - 2017 Jokioinen - 2017 Lavias
Fig. 1 DON accumulation (DON), germination capacity (GC) and Fusarium infected kernels (FIK) plotted from the field experiments where the traits were measured. The upper figures show the data for all the genotypes in different field experiments and the lower figures show the data for seven selected oat genotypes

\section{Results}

Fusarium associated traits estimated from a variable data set

In the greenhouse experiments, a high rate of FIK and DON was achieved, and the two check cultivars were constantly separated from each other (Table 1, S2). In the field experiments (Table 2) the average DON, FIK and GC varied highly from experiment to another, which also affected the differentiation of the oat genotypes (Fig. 1). For example, one of the field experiments in 2013 (Jokioinen II) and another in 2015 (Jokioinen) had almost no DON, while the experiment in Laukaa in

Table 3 The range and number $(\mathrm{N})$ of oat genotype specific DON accumulation estimates for different types of accessions based on the entire data for the greenhouse ( 8 experiments) and field (13
2017 had a wide variation concerning both DON and GC. The GC was much reduced in the 2013 Jokioinen II trial, but not in the 2015 Jokioinen trial.

The FHB susceptibility based on DON or FIK differed between entries depending on whether the oat genotypes were grouped greenhouse or field (Tables 3 and 4). This was verified by significant $\mathrm{G} \times \mathrm{E}$ interactions that were detected for both DON $(P<0.05)$ and FIK $(P<0.001)$.

DON in the field and greenhouse experiments

The average DON did not differ significantly between the greenhouse (mean $\pm \mathrm{SD}, 8600 \pm 11,000 \mu \mathrm{g} / \mathrm{kg}$ ) and

experiments). We show separate ranges for all estimates and for estimates that have data collected from a minimum of three experiments

\begin{tabular}{|c|c|c|c|c|c|c|c|c|}
\hline \multirow[t]{3}{*}{ Type of material } & \multicolumn{4}{|l|}{ All estimates } & \multicolumn{4}{|c|}{ Estimates with data from min. Three experiments } \\
\hline & \multicolumn{2}{|l|}{ Greenhouse } & \multicolumn{2}{|l|}{ Field } & \multicolumn{2}{|l|}{ Greenhouse } & \multicolumn{2}{|l|}{ Field } \\
\hline & Range & $\mathrm{n}$ & Range & $\mathrm{n}$ & Range & $\mathrm{n}$ & Range & $\mathrm{n}$ \\
\hline Breeding lines & $3279-10,531$ & 10 & $652-57,891$ & 212 & $3279-7526$ & 7 & $5007-17,398$ & 176 \\
\hline Cultivars & $805-22,059$ & 13 & $7204-27,382$ & 27 & $4792-22,059$ & 3 & $7204-20,138$ & 22 \\
\hline Accessions & $462-9904$ & 14 & $5026-22,691$ & 14 & $462-9904$ & 14 & $5026-22,691$ & 14 \\
\hline
\end{tabular}




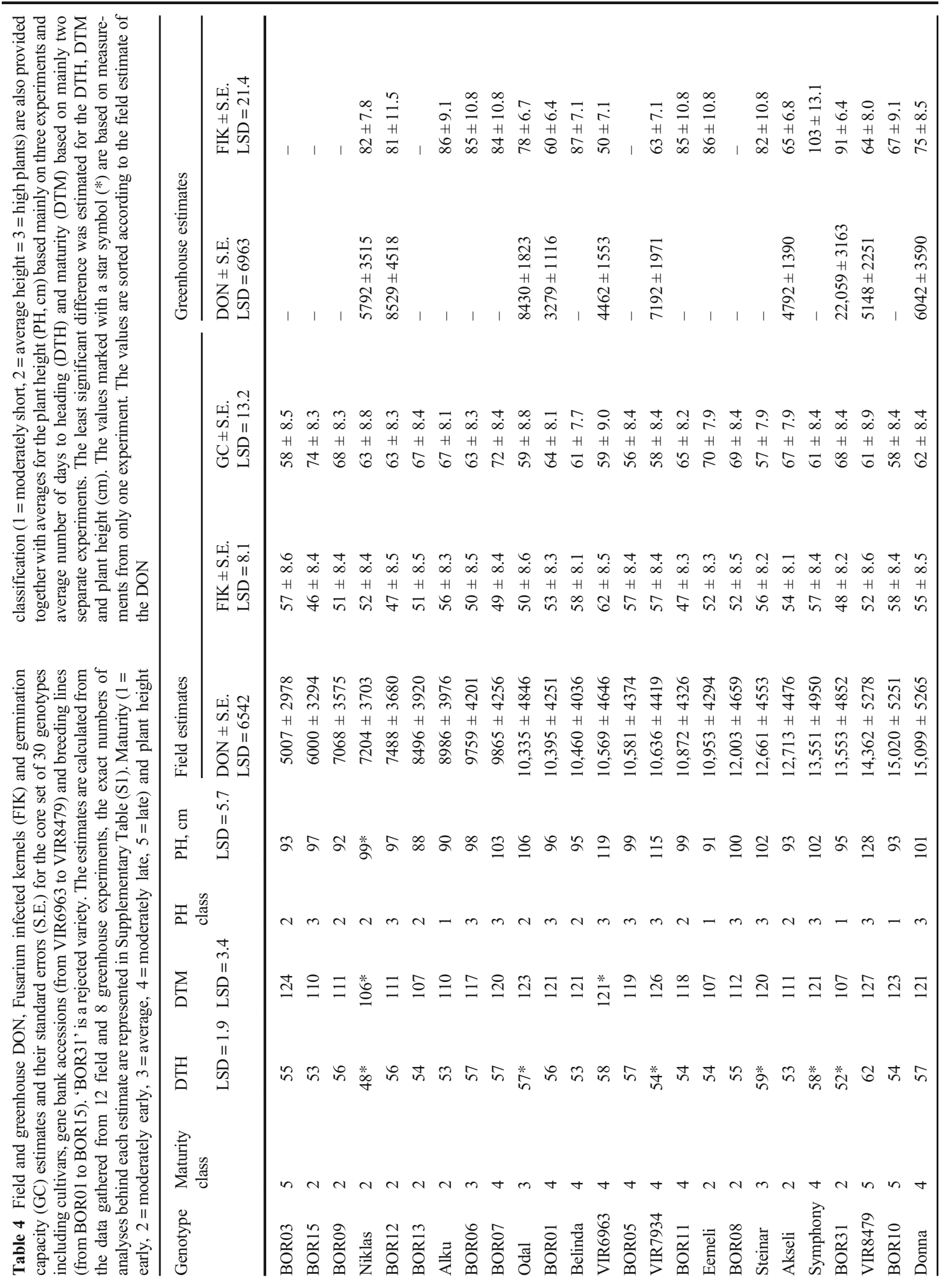


field (mean $\pm \mathrm{SD}, 22000 \pm 21,000 \mu \mathrm{g} / \mathrm{kg}$ ) environments $(P=0.13)$. Both the greenhouse and field screening experiments separated oat genotypes which had high differences in their DON $(\mathrm{P}<0.001$, Tables 3 and 4). When the estimates for DON from the field experiments were plotted with the DON from the greenhouse experiments (S3), only the hulless oat genotypes could be differentiated as a more resistant group in both environments. Whereas, when comparing the DON estimates, we found that the rejected variety 'BOR31' stood out as an outlier with a clearly higher DON in the greenhouse experiments than any other line. However, in field its estimate was only slightly higher than average estimates (Table 4, Fig. 2d, S3). The variation in DON within breeding lines was higher than the variation for the cultivars or gene bank accession. However, it should be noted that when the best linear unbiased estimators (BLUEs) based on a minimum of three experiments are considered (Tables 3 and 4), the lowest DON for the field experiments can be found among the breeding lines and the highest for the breeding lines are lower than the highest estimates for the cultivars or gene bank accessions.

Fusarium infected kernels in the field and greenhouse experiments

The average FIK for the greenhouse $(82 \%)$ and field $(55 \%)$ experiments differed significantly $(P<0.05)$. If all the FIK samples would have been counted similarly (after 7 days of incubation), the respective percentages would be $83 \%$ for the greenhouse experiments and $92 \%$ for the field experiments. Nevertheless, both the greenhouse and field screening experiments also separated oat genotypes with high differences and those with differences in their Fusarium infected seeds $(P<0.001$, Table 4$)$. According to a statistical power analysis (S4) and the standard errors for FIK in Table 4, the greenhouse analysis for FIK was more sensitive than the field analysis in finding genotypic differences. Two greenhouse experiments were enough to separate two genotypes with less than a $20 \%$-unit difference in the FIK, but for the field samples at least three experiments were needed.

The FIK variable had a highly positive correlation with DON in the greenhouse experiments (Table 1), but in the field experiments the correlations were lower (Table 2). However, when the correlation between the 

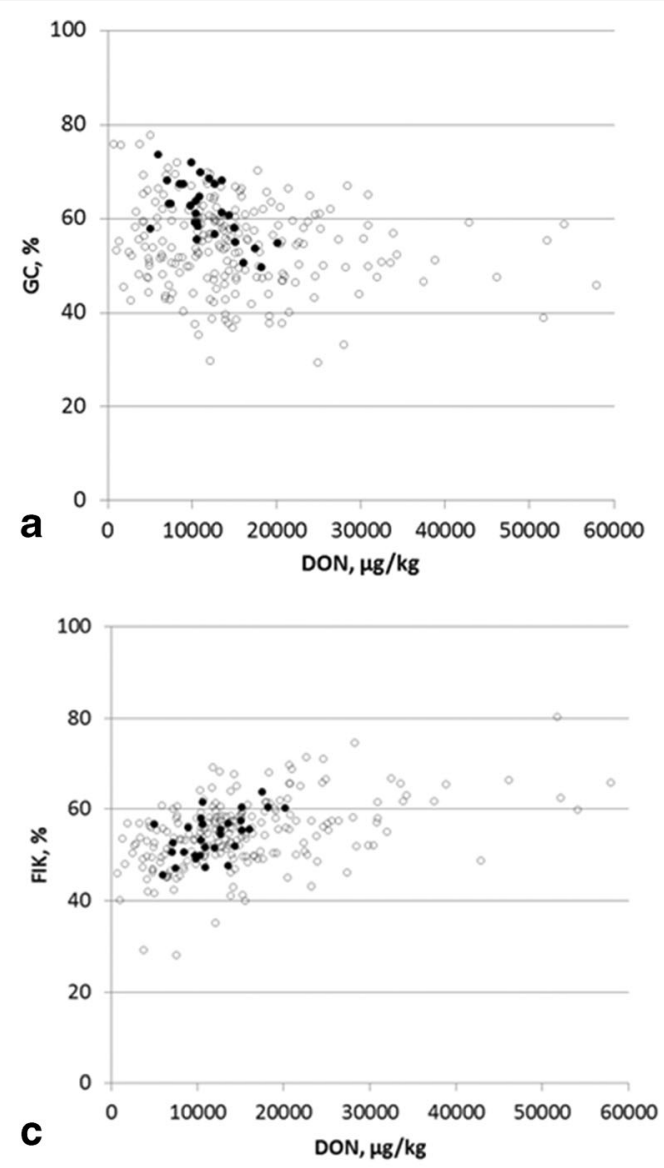

Fig. 2 The relationships between estimates (BLUEs) for DON accumulation (DON), Fusarium infected kernels (FIK) and germination capacity (GC) in the field experiments (2a-2c) and

BLUEs of the genotypes (Fig. 2b) was studied there were clear correlations in field experiments both for all genotypes $(\mathrm{r}=0.43, P<0.001)$ and for the core set of 30 oat genotypes $(\mathrm{r}=0.52, P<0.01)$. In contrast, in the case of the greenhouse experiments there was no significant correlation detected between the oat genotype estimates for DON or FIK (Fig. 2d). On average, the gene bank accessions had significantly lower rates of FIK both in the greenhouse (P $<0.001)$ and field $(\mathrm{P}<0.001)$ experiments when compared to the cultivars and breeding material. The hulless genotypes stood out with low FIK values both in the field and greenhouse experiments. When the FIK estimates were plotted for the field and greenhouse experiments there was no clear relationship between them, but the most resistant genotype, 'VIR11012' stood out as an outlier with clearly lower FIK rates in both environments (S3).
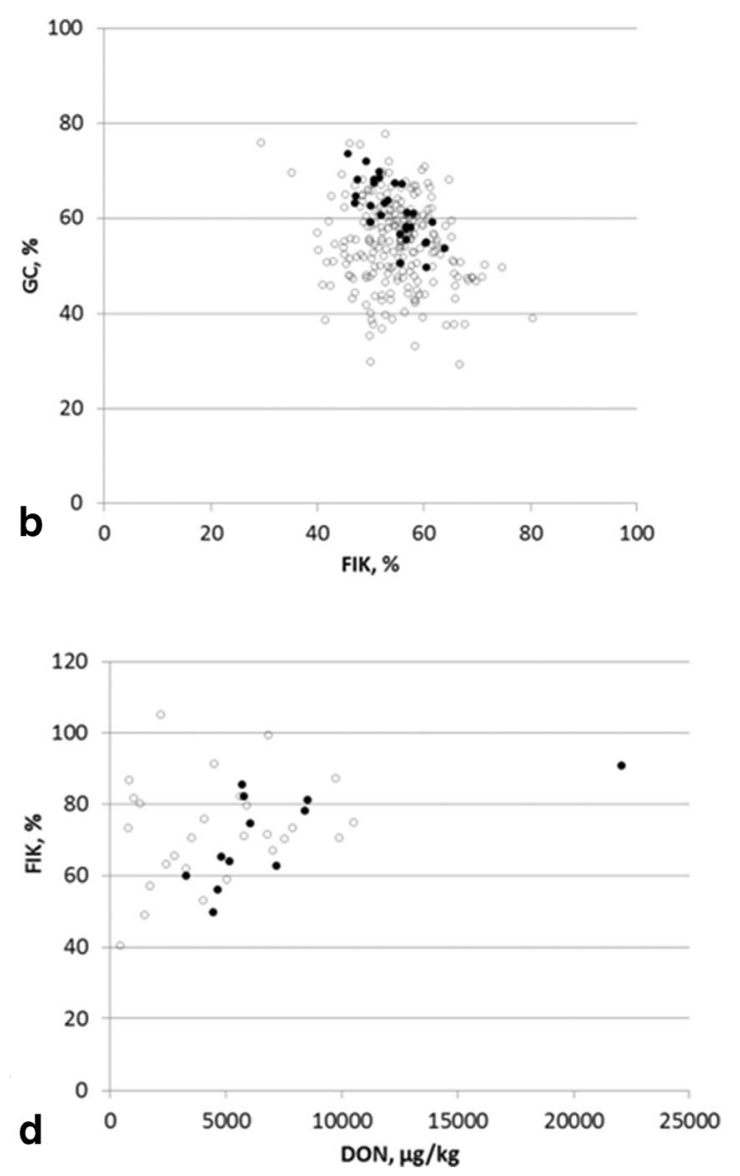

greenhouse experiments (2d). White dots represent all the genotypes' estimates and black dots represent the estimates for the core set of 30 oat genotypes

Germination capacity and its interaction with DON and FIK.

The average germination time for oats in the Fusarium inoculated field trials (mean $\pm \mathrm{SD}, 58 \pm 25 \%$ ) was significantly affected by the oat genotype $(P<0.001)$ factor. According to a statistical power analysis (S4) the least significant difference concerning the germination capacity in the core set was less than $15 \%$-units. Thus we can also see clear variation within this trait. DON had a highly negative correlation with the GC variables (Table 2). The BLUEs for the GC within the core set correlated well with both the BLUEs for the FIK ( $\mathrm{r}=$ $-0.73, P<0.001)$ and DON $(r=-0.61, \mathrm{P}<0.001)$ (Fig. 2 ). When plotting the GC values with the DON or FIK (Fig. 2a and b)2c) values there was good linearity within the core set of estimates, but for all estimates the correlations for the $\mathrm{GC}$ were weaker $(\mathrm{r}=-0.21, P<0.001$ for 
DON and $\mathrm{r}=0.17, P<0.001$ for FIK). Good estimates of the GC often coincide with low DON or FIK estimates, but the ranking of DON estimates does not completely follow the ranking of the FIK or the GC estimates (Table 4, Fig. 2). The germination rankings of 47 oat genotypes changed significantly in one group of experiments with a high level of DON contamination compared to another group of experiments with a low level of DON contamination $(\mathrm{P}<0.001)$.

Passive resistance mechanisms

Hulless oats were more resistant than hulled accessions $(\mathrm{P}<0.001)$. The most resistant gene bank accession among all the studied genotypes was the hulless landrace 'VIR11012' with a very low estimate for DON in the greenhouse $(462 \mu \mathrm{g} / \mathrm{kg})$ experiments and a moderately low DON in the field $(7525 \mu \mathrm{g} / \mathrm{kg})$ experiments. The other four hulless oat genotypes included in our data also had good estimates ranging between 5025 and $11,692 \mu \mathrm{g} / \mathrm{kg}$ and between 1720 to $5600 \mu \mathrm{g} / \mathrm{kg}$ in the field and greenhouse experiments, respectively.

In the field experiments, the $\mathrm{PH}$ and maturity classes had significant impacts on DON $(\mathrm{P}<0.001)$ and FIK estimates $(\mathrm{P}<0.001$, Table 5). $\mathrm{PH}$ also impacted the GC $(P=0.01$, Table 5). The shortest plants (height class 1$)$ had significantly more DON (mean $19,042 \mu \mathrm{g} / \mathrm{kg}$ ) than the intermediate height plants in class $2(16,740 \mu \mathrm{g} / \mathrm{kg}$, $P<0.01$ ). The tallest oat genotypes (class 3 , mean $17,928 \mu \mathrm{g} / \mathrm{kg}$ ) did not significantly differ either from the lowest or the intermediate class in their DON. Class 3 included several lines from VIR with measured heights of around $120 \mathrm{~cm}$ (Table 4). The shortest plants (height class 1) had more FIK (69\%) than the tallest plants in class $3(66 \%, P<0.05)$. Intermediate height plants (class 2) had lower GC than the shortest plants ( 52 vs. $55 \%, \mathrm{P}<0.05$ ), but these did not differ from the tallest plants.

The early and average maturing oat accessions had significantly less DON than the late maturing oats (Fig.3). The FIK estimates for different maturity classes were similar to the DON estimates, but their differences were relatively small. Late and very late maturing genotypes did not differ significantly from each other concerning their FIK (at 57-58\%), whereas the earliest maturing (the 1st column in Fig. 3) genotypes had FIK estimates of $51 \%$.
Moderately resistant and highly susceptible oat genotypes in the core set of genotypes

The genotype estimates for DON, FIK and GC with only one or two experiments suffered from high variation (Table 3) and low accuracy (S4). Thus, the core set of estimates was formed with a higher number of experiments (Table 4 and Fig. 2). The core set contained estimates from genotypes which were included in a minimum of three field experiments and two greenhouse experiments (S1). The breeding line 'BOR03' presented in the core set had the lowest DON in field of all the studied genotypes (Fig. 2). Contrastingly, 'BOR03' had a relatively low GC, whereas the breeding line 'BOR15' had the second lowest DON in combination with better germination capacity (Table 4). These two lines differed mostly in how early they matured, since 'BOR03' had a higher DTM requirement. 'BOR03' is an exception since late maturity was commonly followed by high DON contents in the CORE set (Table 4). When the rank correlation between Fusarium associated traits and DTM, DTH and PH were studied in the core set only DTM showed significant correlations. The coefficients of correlation were $-0.76(P<0.001), 0.48$ $(P<0.01)$ and $0.58(\mathrm{P}<0.001)$ for the GC, DON and FIK estimates, respectively.

The cultivar 'Niklas' had the lowest DON accumulation (estimate $7204 \mu \mathrm{g} / \mathrm{kg}$ ) among the tested cultivars. The cultivars 'Rocky', 'Obelix' and 'Mirella' were identified as highly susceptible to DON (estimates $17,490,18,168$ and $20,138 \mu \mathrm{g} / \mathrm{kg}$, respectively) (Table 4). These oat genotypes with the highest DON values also had the lowest GC in the Fusarium inoculated field trials (Table 4). When the most susceptible cultivar 'Mirella' and the most resistant cultivar 'Niklas' are compared in Table 4 it can be seen that the greatest difference between these lines is in the DTM (Table 4).

From Table 4 it can be seen that hulled gene bank accessions also contained promising genotypes such as 'VIR6963', which had relatively low DON estimates both in the field and greenhouse experiments and had the lowest estimate for FIK of the hulled genotypes in the greenhouse (Table 4). Contrastingly, a gene bank accession 'VIR7766', with a similar PH and maturity to 'VIR6963' had similar DON values in the greenhouse, but a very high DON in the field (Table 4). 
Table 5 The results from analyses of variance on the impact of the plant height and maturity on the classification of the three Fusarium resistance parameters: DON accumulation (DON), Fusarium infected kernels (FIK), germination capacity (GC) in field conditions

\begin{tabular}{llll}
\hline Trait & DON & FIK & GC \\
\hline Plant height & $\mathrm{df}=1402 \mathrm{~F}=9.70 \mathrm{P}<0.001$ & $\mathrm{df}=2256 \mathrm{~F}=8.03 \mathrm{P}<0.001$ & $\mathrm{df}=1213, \mathrm{~F}=3.81, \mathrm{P}=0.01$ \\
Maturity class & $\mathrm{df}=1397 \mathrm{~F}=27.95 \mathrm{P}<0.001$ & $\mathrm{df}=2245 \mathrm{~F}=13.40 \mathrm{P}<0.001$ & $\mathrm{df}=1222, \mathrm{~F}=2.02 P=0.09$ \\
\hline
\end{tabular}

\section{Discussion}

Analysing unbalanced data

The primary aim of this investigation was to study data from various experiments in order to test whether a better understanding of the variation of Fusarium infections and DON in oat genotypes in various experimental situations/ environments could be achieved. A combination of field and greenhouse experiments were carried out without reducing any experiments from the data set in order to see how FHB resistance can be estimated based on such diverse data. High variations in the original DON data (from 19 to $126,000 \mu \mathrm{g} / \mathrm{kg}$ ) produced a range of oat genotype-specific mycotoxin estimates varying from less than one thousand to $58,000 \mu \mathrm{g} / \mathrm{kg}$ in the field experiments and less than one thousand to $22,000 \mu \mathrm{g} / \mathrm{kg}$ in the greenhouse experiments. Even with estimates based on more than three field trials, the difference between the lowest and highest DON estimates was more than $15,000 \mu \mathrm{g} / \mathrm{kg}$. Our data support the claim by Bjørnstad et al. (2017) that the separation oats with varying degrees of susceptibility to DON with a significant difference of at least below $3000 \mu \mathrm{g} / \mathrm{kg}$ of DON can be achieved by conducting a sufficient number of inoculated field or greenhouse experiments.

Our method involved an analysis of available experiments together instead of a step-wise approach (Piepho et al. 2012) in which multi-environment experiments are first analysed individually and then the larger set is studied based on the best linear unbiased predictors (BLUPs). Since our research focused on estimating how the selected set of oat genotypes behaved in these specific field experiments and greenhouse experiments, the use of BLUEs instead of BLUPs was necessary to consider the genotypes as fixed factors. Unbalanced data is recognized as one of the major problems when linear methods or other traditional methods are applied in agricultural sciences. In the case of unbalanced data, major treatments (e.g. genotypes) dominate minor treatments, leading to bias in the estimated means and their standard errors. When comparing different genotypes over a range of many years, the set of genotypes cannot be fixed at the outset of the study. Typically, new interesting genotypes are constantly added and some of the older ones will be found to be no longer relevant.
Fig. 3 The estimates and standard error for the DON values and infection percentages according to the maturity class ( 1 = early, 2 = moderately early, $3=$ average, $4=$ moderately late, $5=$ late). Classes 1, 2 and 3 differ significantly $(\mathrm{P}<0.05)$ from classes 4 and 5 which also differ significantly from each other $(\mathrm{P}<0.05)$. The number of oat genotypes (n) within classes is indicated behind the class numbers

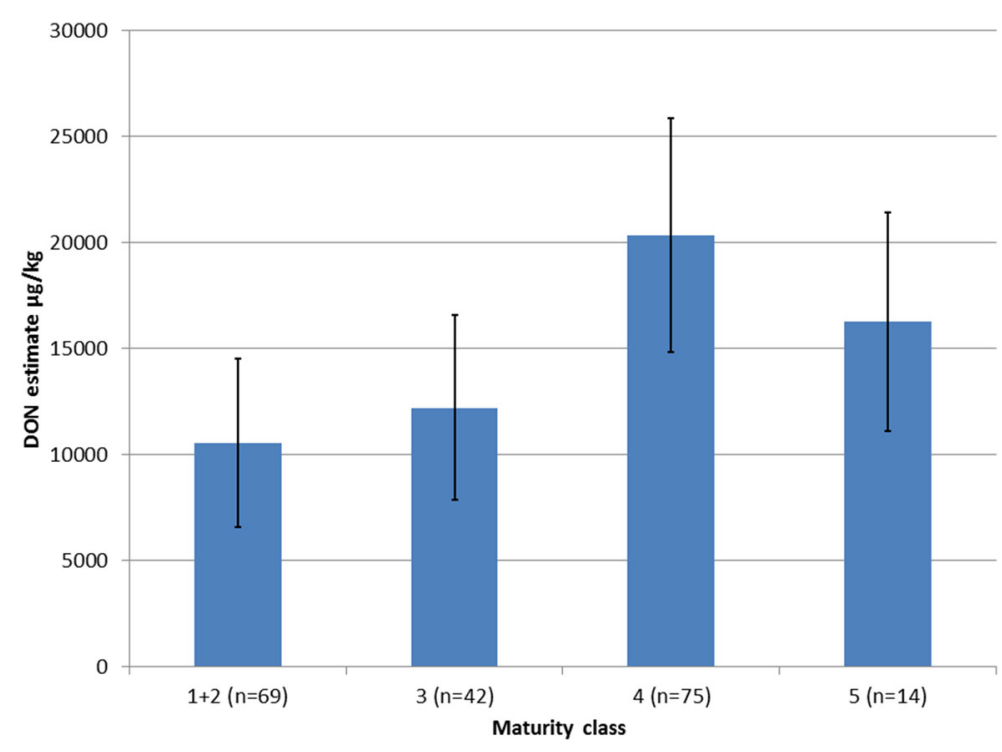


Searle (1987) suggested that the genotype effects can be estimated in any well-defined linear mixed model analysis if the turnover of genotypes tested is less than $20 \%$. Careful monitoring of the annual turnover is needed. After that, a statistical analysis can be made without bias. The protocol that was applied here resulted in valid estimates and their standard errors for all genotypes. The REML method used here was very similar to the one recommended by Piepho and Moehring (2006) to avoid bias caused by selection during breeding trials. In this study we have shown one possible way of analysing unbalanced data and demonstrated the potential effectiveness of utilizing data between greenhouse and field trials.

High range of DON estimates

The range of DON estimates in different types of material indicates that considerable variation in the resistance response already exists in breeding programmes and in the cultivars used in Finnish oat production. The comparison of greenhouse and field estimates also underlines the role of a suitable PH and DTM in disease resistance, since the resistant gene bank accessions with generally good estimates in the greenhouse experiments all had estimates ranging from low to very high DON in the field. In Nordic field conditions a robust stem and early maturation seemed to play an important role in FHB resistance. Additionally, selecting for yield under high Fusarium incidence typical to Nordic conditions may have maintained some resistance of the breeding populations since Fusarium infections can have significant impacts on oat yields (Martinelli et al. 2014) and also yields of other cereals (Nganje et al. 2004). This hypothesis is also supported by similar results from screenings of Norwegian and Canadian germplasm (Tekle et al. 2018, Yan et al. 2010).

The overall good performance of the gene bank accessions in the greenhouse suggests that unused resistance sources exist within these weakly adapted accessions. The use of exotic germplasm in breeding is complicated due to the linkage drag of undesirable traits, and it can also be practically constrained by weak seed setting between crosses. Hulless gene bank accessions were excluded from our experiments after 2016 because hulless oats are very marginally produced and the resistance in hulless oats is suggested to be mainly related to the absence of hulls (Tekle et al. 2018). Since the hulless genotypes included in our experiments also had undesirable agronomical characteristics such as high rates of lodging, it was not seen useful to study these accessions further as potential resistance sources. Nevertheless, the reduction of genetic diversity during the shift from landraces to modern varieties is significant (He and Bjørnstad 2012). Therefore, pre-breeding through crossings between exotic accessions and modern genotypes followed by backcrossing could be a valuable initiative which could increase both the diversity and Fusarium resistance of oat breeding populations. However, in the near future the quickest results in resistance can be achieved within breeding populations through efficient phenotyping.

\section{Different estimates from field and greenhouse}

Due to higher variation, the field experiments need to be replicated more than the greenhouse experiments. This also appears in the statistical power analyses (S4), where two greenhouse experiments are sufficient to separate genotypes, but in the field similar difference require more than three experiments to become significant. However, the different resistance estimates obtained from the field and greenhouse trials indicate that these platforms should be applied for different purposes.

Hulless lines were pointed out as very resistant in both the field and greenhouse estimates which could encourage the use of the phenotyping of Fusarium resistance in controlled environments searching for potentially superior resistance sources for pre-breeding material. However, it is likely that some of the QTLs contributing to resistance or susceptibility are missed if greenhouse screening alone is applied. In controlled conditions and with targeted inoculations the Fusarium spores are more likely to reach susceptible plant tissues in all different host genotypes at the most susceptible time. The impact of the environment on the infection pressure is somewhat similar during all the infection occasions in the greenhouse because of the directed and standardized inoculum and stable moisture, light and temperature conditions. When all the panicles are inoculated directly by spraying during anthesis, the impact of escape factors such as the $\mathrm{PH}$ and flowering time become clearly less significant than in field conditions. This makes greenhouse testing an efficient tool to evaluate resistance that occurs once the Fusarium spores have reached the floral tissue and resistance mechanisms start to act. This could be used as supplementary information for field testing results to confirm that the 
resistance of crossing parents also contains cell related mechanisms, for example.

In an open field the infection pressure may be continuous, and infections occur from beginning of flowering to yellow maturity (Tekle et al. 2012). Especially with the spawn inoculation method for oats (Tekle et al. 2013, Tekle et al. 2018) that was used in most of the field experiments of this study, the environment is kept in a continuously disease promoting state and inoculum is left on the field to spread the disease. Secondary infections and continuous spore release from the original inoculum (Tekle et al. 2013, Tekle et al. 2018) allow all resistance mechanisms, from the evasion of initial infection to pathogen induced systemic defences (Walter et al. 2010), to play a role. For this reason the results from field experiments are better at reflecting the situation that exists on farmers' fields in Finland, especially in the worst disease years. The Finnish cereal committee compared oat cultivars and their mycotoxin levels based on analyses reported by cereal traders and the food industry between 2014 and 2017 (Finnish cereal committee's website, accessed 6.2.2019). The median values presented for DON, especially from the heavy FHB year of 2016, agree with our findings showing that the cultivars 'Rocky' and 'Obelix' were the most susceptible ones. Moreover, the cultivars that had an average or moderately low DON in our data do not raise concerns in that study either. Similarly, (Gagkaeva et al. 2013) found that most of their oats which had been screened for resistance under artificially inoculated field conditions behaved similarly in a site under natural infection conditions. The results of this study also agree with the rankings obtained from Norwegian spawn inoculated field trials (Tekle et al. 2018), e.g. the cultivars 'Odal', 'Akseli' and 'Mirella' rank very similarly, although the 'Odal' cultivar was not as distinctive in our study as it was in Norway.

\section{DON and Fusarium infected kernels}

In wheat studies the relationship between infection traits such as Fusarium damaged kernels or symptomatic spikelets and DON can be seen in both field and greenhouse conditions (Devkota et al. 1999, Jin et al. 2014), although differences in the infection pressure, for example, can affect the relationships between these two environments (Jin et al. 2014). In our study, the correlations between FIK and DON analyses were high in the greenhouse, but in the field the correlation between the variables was usually lower and more variable but still significant. Table 2 shows clear Spearman rank correlations between FIK and DON and FIK and GC. However, estimating the correlation across all trials does not give reliable results for the correlation between DON and FIK. One reason for this may be that there are very different numbers of entries in different trials which make the ranks less compatible. Figure 1 shows that the negative correlations between field FIK and DON samples in Table 1 are most likely to be a result stemming from the difference in the assessment of the FIK samples. The FIK values from the most severe infection years were calculated after three days of incubation, whereas in the other experiments the calculation was done after one week and this is why there are two peaks in Fig. 1 which plots DON against FIK.

There were no clear relationships between DON observed in the field and greenhouse or the FIK observed in the field and the greenhouse even in the core set of estimates (S3). The above mentioned differences in variation of climatic factors and the external infection pressure between field and greenhouse environments can explain this weak relationship. In addition, the amount of DON can be considered as an outcome of the host and pathogen interaction. However, the FIK ratings that have been derived from the seeds in this study mainly reflect the incidence of infections without giving any information on how superficial they were. The variations in timing, duration and severity of $\mathrm{Fu}$ sarium infections are likely to impact the results. Continuous infection in the field leads to a higher proportion of infected seeds within panicles and thus it can increase the quantity of mycotoxins. However, if the conditions are not optimal for infection there may be a high number of mildly infected seeds with lower mycotoxin accumulations, but these still may have a good chance of not germinating (Tekle et al. 2013, Tekle et al. 2018). Despite a strong correlation between FIK and DON in the greenhouse, there are several examples indicating that also DON can be dependent on other factors than the number of infections (Table 4, Fig. 2). For example comparison of genotypes such as 'BOR04', 'VIR8479' or 'VIR7766' and 'VIR6963' can show differing responses in their traits depending on environment.

Since the interpretation of FIK can be cumbersome, especially when infections reach $100 \%$, we would recommend quantitative PCR to be used for quantifying the incidence and severity of Fusarium infection in future. 
Góral et al. (2019) compared different FHB resistance parameters in wheat and found fungal biomass to be the best predictor for DON. In farm samples of oats the correlation between the $F$. graminearum biomass and DON may be more significant than the infection incidence and DON (Yli-Mattila et al. 2017). Speciesspecific primers may also increase the accuracy when compared to the counting of seeds with Fusarium mycelium and may enable the comparison of other Fusarium species and mycotoxins such as F. langsethiae and T2/ HT2 toxin (Edwards et al. 2012).

\section{DON and germination capacity}

The germination capacity does not completely reflect the FHB severity in the experiments, since dead light weighted kernels can be partially lost during threshing and viable fungi also from superficial infections can harm the germ (Tekle et al. 2013). There were both high and low correlations between FIK and GC estimates for oats depending on the experiment, which indicates that this relationship is also strongly affected by the environment. A cool and wet autumn in 2017 affected the germination $\%$ in Finland and is likely to explain the high range of GC in our experiments that year.

In Tekle's studies, the correlations between DON and GC were stronger in drier rather than in wet years and in spray inoculated rather than spawn inoculated experiments (Tekle 2014). These results indicate that infection during anthesis is more likely to lead to severe infection also affecting the GC and DON, whereas in wet years, the GC is affected also by the weather and by the increased inoculum, which increases superficial infections after anthesis. In wet years, there is also higher infection pressure from other pathogens than Fusarium ssp. contributing to lower GC, which may be the case in those experiments that had low GC and low DON. The highly negative correlation between GC and DON is a result from both the proliferation of the fungal biomass which affects the germ and also damage caused by the infection and mycotoxins. Even relatively low amounts of DON have been shown to cause abnormal seedling growth in oats (Tekle et al. 2013) which would not be regarded as healthy germinated seeds in our germination assays. The dead kernels killed by infection are not germinating seeds either. Thus resistance against infection, tolerance to mycotoxins and tolerance to infection can all protect the germination capacity from Fusarium infections.
Our core set's ranking in GC reveals oat genotypes with tendencies towards high or low GC under severe infection pressure. There are also clear outliers such as 'BOR03' with low DON and relatively low GC values. This abnormality could be explained by the wet weather in 2017 and the longer DTM requirements this entails. However, 'BOR03' also has a relatively high FIK estimate indicating that it has been highly infected in many experiments. Thus, the mechanism in this case may be resistance to DON or detoxification. The significant interaction from the analysis made for $\mathrm{GC}$ in two groups of experiments with different DON levels suggests that some of these genotypes are able to tolerate DON better than others. The experimental data were not sufficient to calculate significant differences for the oat genotypes between these two groups, but nevertheless this indicates that different mechanisms can affect the germination of Fusarium infected oats. The inconsistence between DON levels (4x) and GC levels (similar) between these groups of experiments may also result from environmental conditions and from the different infection pressure. The correlations in different field experiments (Table 2) and their visualization in Fig. 1 also support this. In future, the development of high-throughput automatic germination scoring methods (Joosen et al. 2010) could make germination analyses more costefficient and widely used for FHB resistance as well. Digital image analysis has shown promise also as an alternative to visual scorings of FHB severity in triticale (Ollier et al. 2020).

The role of passive resistance mechanisms

Differences in the mycotoxin accumulation in oats seem to be largely affected by the severity of the initial infection. Passive resistance mechanisms can increase type I resistance through different mechanisms leading to the prevention or evasion of infection. Prolonged growing times from emergence to flowering, increased $\mathrm{PH}$ and increased grain numbers per panicle all led to reduced incidences of Fusarium infections in surface sterilized grains in the screening of the VIR gene bank material (Loskutov et al. 2016). In our data the shortest plants had the highest FIK and DON, but some of the tallest plants differed less from the shortest plants than the intermediate height class 2 plants did. These tall plants were mainly gene bank accessions, with a high rate of lodging (data not shown). Moreover, the tallest plants also had a long growing period especially from 
flowering to maturity which may have increased their susceptibility, as was also observed in the study by Loskutov et al. (2016). A long stem can provide protection from Fusarium infections, but it should also be robust, and the increased $\mathrm{PH}$ should not increase lodging. The oat genotype 'BOR31' was relatively short and it was also one of the earliest flowering and maturing oat genotypes in this study. Early maturation may partly explain why 'BOR31' was less susceptible in the field than in the greenhouse. Late maturing oats are more likely to face moister autumn weather, which can promote the accumulation of DON toxins especially when they are suitably timed with the right temperature (Hjelkrem et al. 2017, Kaukoranta et al. 2019). However, again the breeding line 'BOR03' is an outlier in Table 4 and an example of an oat with good mycotoxin resistance combined with late maturity.

In addition to the $\mathrm{PH}$, early maturation and lodging, there are also other interesting traits that could be studied. For example, Tekle (2014) suggest that future studies should investigate the importance of anther extrusion as a passive resistance mechanism. There is evidence that oat genotypes with relatively high or relatively low anther extrusion are shown to be less prone to accumulating Fusarium mycotoxins (Herrmann et al. 2020). More detailed studies of different active and passive resistance parameters, including for example anther extrusion and also yield parameters to determine tolerance, could further enlighten the structure of FHB resistance in oats. The core set of this study is included in our ongoing studies, and thus more detailed information will be provided in the future.

\section{Conclusions and future prospects}

The common phenomenon that the impact of Fusarium infection varies between different environments was shown. Different oat genotypes were shown to have highly differing responses depending on the resistance parameter measured, which may be a sign of different genes and gene interaction impacting the resistance. Therefore, several check cultivars representing the variation of different resistance components should be included in trials as mentioned by Bjørnstad et al. (2017). In the greenhouse environment, the proportion of infected seeds could be used as a light screening method to select potentially resistant and susceptible lines and parents for pre-breeding. However, in order to achieve lines with a working resistance the phenotyping needs to be confirmed in field conditions. In addition, testing should at least include measurements of DON, Fusarium content and germination percentage of the kernels. Moreover the variation in $\mathrm{PH}$ and maturation time in the field should be considered and if possible dealt with in the experimental design either by studying the resistance on oat genotypes of a similar $\mathrm{PH}$ and maturation time together or by including these factors into the statistical model used for analysis.

The results of this study on the suitability of methods and the need for repetition to assess FHB infections in oats can be used to improve phenotyping for Fusarium resistance. Proper phenotyping is needed to utilize genomic selection in the development of more resistant cultivars. Genomic prediction is based on a training population in which the genotypes are thoroughly phenotyped and genotyped. A genomic prediction approach has been successfully used when selecting Fusarium resistance for winter wheat (Rutkoski et al. 2012, Arruda et al. 2015) and for spring wheat (Dong et al. 2018). A similar approach could well work with oats, where Fusarium resistance is likely to be controlled by numerous loci with small effects (Bjørnstad et al. 2017, He et al. 2013). However, because visual scoring for resistance is not feasible for oats (Tekle et al. 2018); other reliable evaluation methods are needed. Moreover, there is still a need for cost efficient methods to measure DON content or germination, since both of these methods become very costly for large populations. The use of hyperspectral imaging in the prediction of DON contamination has been suggested as a potential method for oats (Tekle et al. 2015) and also for wheat (Barbedo et al. 2016). The disadvantage of these imaging methods may be that these methods estimate DON indirectly via kernel traits, which may vary largely in different environments and with different genetic backgrounds. Further research to understand the interaction between the host and the pathogen will be valuable for determining additional factors contributing to Fusarium resistance in oats.

Acknowledgements The Raisio plc Research Foundation, Makera funding of Finnish Ministry of Agriculture and Forestry (diary number: 1692/03.01.02/2015) and Tekes (Grant 1565/31/ 2015 to Boreal Plant Breeding Ltd.) are acknowledged for funding this research. Boreal plant breeding Ltd. played an essential role in conducting many of the field trials to produce the data and the company also supported the project financially by providing supplementary data, knowledge and conducting all of the mycotoxin analyses. From Luke the authors would like to warmly thank the technical staff of the Vitrinia building in Jokioinen, especially Auli Kedonperä, Tuula Viljanen, Aila Siren and Marjaana Virtanen. 
Senior Scientist Päivi Parikka is acknowledged for her generous advice especially on the Fusarium isolates and greenhouse inoculations. Technicians Hannu Tiainen and Jorma Moilanen at the Laukaa research station and farmer Mauri Räkköläinen are acknowledged for helping us with the Laukaa field experiments.

Funding Information Open access funding provided by Natural Resources Institute Finland (LUKE).

\section{Compliance with ethical standards}

Conflict of interests The authors declare that they have no conflict of interests.

Ethical statement The research presented in this manuscript did not involve any animal or human participants.

Open Access This article is licensed under a Creative Commons Attribution 4.0 International License, which permits use, sharing, adaptation, distribution and reproduction in any medium or format, as long as you give appropriate credit to the original author(s) and the source, provide a link to the Creative Commons licence, and indicate if changes were made. The images or other third party material in this article are included in the article's Creative Commons licence, unless indicated otherwise in a credit line to the material. If material is not included in the article's Creative Commons licence and your intended use is not permitted by statutory regulation or exceeds the permitted use, you will need to obtain permission directly from the copyright holder. To view a copy of this licence, visit http://creativecommons.org/licenses/by/4.0/.

\section{References}

Afanasenko, O. S., Jalli, M., Pinnschmidt, H. O., Filatova, O., \& Platz, G. J. (2009). Development of an international standard set of barley differential genotypes for Pyrenophora teres $\mathrm{f}$. teres. Plant Pathology, 58(4), 665-676.

Anand, A., Zhou, T., Trick, H. N., Gill, B. S., Bockus, W. W., \& Muthukrishnan, S. (2003). Greenhouse and field testing of transgenic wheat plants stably expressing genes for thaumatin-like protein, chitinase and glucanase against Fusarium graminearum. Journal of Experimental Botany, 54, 1101-1111.

Arruda, M., Brown, P., Lipka, A., Krill, A., Thumber, C., \& Kolb, F. (2015). Genomic selection for predicting Fusarium head blight resistance in a wheat breeding program. Plant Genome, 8(3).

Barbedo,A., Tibola, J.G., Pontes, C.S. \& Lima, M.I. (2017). Deoxynivalenol screening in wheat kernels using hyperspectral imaging. Biosystems Engineering, 155, 24-32.

Bjørnstad, Å., He, X., Tekle, S., Klos, K., Huang, Y., Tinker, N. A., Dong, Y., \& Skinnes, H. (2017). Genetic variation and associations involving Fusarium head blight and deoxynivalenol accumulation in cultivated oat (Avena sativa L.). Plant Breeding, 136, 620-636.

Buerstmayr, H., \& Lemmens, M. (2015). Breeding healthy cereals: Genetic improvement of Fusarium resistance and consequences for mycotoxins. World Mycotoxin Journal, 8, 591-602.

Dill-Macky, R., \& Jones, R. K. (2000). The effect of previous crop residues and tillage on Fusarium head blight of wheat. Plant Disease, 84(1), 71-76.

Dong, H., Wang, R., Yang, Y., Anderson, J., Pumphrey, M., Zhang, Z., \& Chen, J. (2018). Evaluation of the potential for genomic selection to improve spring wheat resistance to Fusarium head blight in the Pacific northwest. Frontiers in Plant Science., 9. https://doi.org/10.3389/fpls.2018.00911.

Devkota, R. N., Rudd, R.C., Rudd, J. C., \& Jin, Y.. (1999). Diallel analysis of FHB and tombstone kernels in spring wheat evaluated under greenhouse and field conditions. Proceedings 1999 National Fusarium Head Blight Forum, U.S. wheat and barley scab initiative, Sioux Falls, South Dakota, December 5-7, 1999.

Edwards, S. G., Imathiu, S. M., Ray, R. V., Back, M., \& Hare, M. C. (2012). Molecular studies to identify the Fusarium species responsible forHT-2 and T-2 mycotoxins in UK oats. International Journal of Food Microbiology, 156, 168-175.

European food safety author EFSA. (2009). Scientific opinion on the substantiation of health claims related to beta-glucans and maintenance of normal blood cholesterol concentrations. EFSA Journal, 7(9):1254.

European food safety author EFSA. (2011). Scientific opinion on the substantiation of health claims related to beta-glucans from oats and barley and maintenance of normal blood LDL-cholesterol concentrations (ID 1236 1299) increase in satiety leading to a reduction in energy intake (ID 851 852) reduction of post-prandial glycaemic responses (ID 821 824) and "digestive function" (ID 850) pursuant to article 13(1) of regulation (EC) no 1924/2006. EFSA Journal, 9(6):2207.

FAOSTAT. (2016). Crops and livestock products. http://www.fao. org/faostat/en/ - data/TP. Rome, Italy: Database of food and agriculture, Organization of the United Nations. Accessed 11 December 2018.

Finnish cereal committee. (2018). Comparison of oat cultivars based on analysis of 23800 DON samples made by commercial laboratories. https://www.vyr.fi/document/1/676/fd5e6 a4/uutise_43048b6_Kauralajikkeet_ja_DON_2014_2017. pdf Accessed 6 February 2019.

Fredlund, E., Gidlund, A., Sulyok, M., Börjesson, T., Krska, R., Olsen, M., \& Lindblad, M. (2013). Deoxynivalenol and other selected Fusarium toxins in Swedish oats-occurrence and correlation to specific Fusarium species. International Journal of Food Microbiology, 167(2), 276-283.

Gagkaeva, T., Gavrilova, O., Yli-Mattila, T., \& Loskutov, I. (2013). Sources of resistance to Fusarium head blight in VIR oat collection. Euphytica, 191(3), 355-364.

Góral, T., Wiśniewska, H., Ochodzki, P., Nielsen, L. K., Walentyn-Góral, D., \& Stępień, Ł. (2018). Relationship between Fusarium head blight, kernel damage, concentration of Fusarium biomass, and Fusarium toxins in grain of Winter wheat inoculated with Fusarium culmorum. Toxins, 11(1), 2. https://doi.org/10.3390/toxins11010002. 
Hautsalo, J., Jalli, M., Manninen, O., \& Veteläinen, M. (2018). Evaluation of resistance to Fusarium graminearum in oats. Euphytica, 214, 139.

He, X., \& Bjørnstad, Å. (2012). Diversity of north European oat analyzed by SSR. Theoretical Applied Genetics: AFLP and DArT markers.

He, X., Skinnes, H., Oliver, R. E., Jackson, E. W., \& Bjørnstad, A. (2013). Linkage mapping and identification of QTL affecting deoxynivalenol (DON) content (Fusarium resistance) in oats (Avena sativa L.). TAG. Theoretical and Applied Genetics, 126(10), 2655-2670.

Herrmann, M. H., Hautsalo, J., Georgieva, P., Bund, A., Winter, M., \& Beuch, S. (2020). Relationship between genetic variability of flowering traits and Fusarium mycotoxin contamination in oats. Crop Science, 60, 852-862. https://doi. org $/ 10.1002 / \csc 2.20125$.

Hietaniemi, V. (2016). The Fusarium mycotoxins in Finnish cereal grains: How to control and manage the risk. Dissertation: University of Turku.

Hietaniemi, V., Rämö, S., Yli-Mattila, T., Jestoi, M., Peltonen, S., Kartio, M., Sieviläinen, E., Koivisto, T., \& Parikka, P. (2016). Updated survey of Fusarium species and toxins in Finnish cereal grains. Food Additives \& Contaminants. Part A, Chemistry, Analysis, Control, Exposure \& Risk Assessment, 33(5), 831-848.

Hjelkrem, A-G., Torfinn Torp, T., Brodal, G., Aamot, H., Strand, E., Nordskog,B. et al. (2017). DON content in oat grains in Norway related to weather conditions at different growth stages. European Journal of Plant Pathology, 148(3), 577, 594.

Hofgaard, I. s., Aamot, H. u., Torp, T., Jestoi, M., Lattanzio, V. m. t., Klemsdal, S. s., et al. (2016). Associations between Fusarium species and mycotoxins in oats and spring wheat from farmers' fields in Norway over a six-year period. World Mycotoxin Journal, 9(3), 365-378.

ISTA. (2006). ISTA handbook on seedling evaluation (3rd ed.). The International Seed Testing Association (ISTA): Bassersdorf.

Jin, F., Bai, G.-H., Zhang, D.-D., Dong, Y.-H., Ma, L.-J., Bockus, W., \& Dowell, F. (2014). Fusarium-damaged kernels and deoxynivalenol in Fusarium-infected U.S. winter wheat. Phytopathology, 104, 472-478.

Joosen, R. V. L., Kodde, J., Willems, L. A., Ligterink, W., van der Plas, L. H., \& Hilhorst, H. W. (2010). Germinator: A software package for high-throughput scoring and curve fitting of Arabidopsis seed germination. The Plant Journal, 62, $148-159$.

Kaukoranta, T., Hietaniemi, V., Rämö, S., Koivisto, T., \& Parikka, P. (2019). Contrasting responses of T-2, HT-2 and DON mycotoxins and Fusarium species in oat to climate, weather, tillage and cereal intensity. European Journal of Plant Pathology, 155, 93-110. https://doi.org/10.1007/s10658019-01752-9.

Loskutov, I. G., Blinova, E. V., Gavrilova, O. P., \& Gagkaeva, T. Y. (2016). The valuable characteristics of oats genotypes and resistance to Fusarium disease. Vavilov Journal of Genetics and Breeding, 20(3), 286-294.

Mackintosh, C., Lewis, J., Radmer, L., Shin, S., Heinen, S., Smith, L., Wyckoff, M., Dill-Macky, R., Evans, C., Kravchenko, S., Baldridge, G., Zeyen, R., \& Muehlbauer, G. (2007). Overexpression of defense response genes in transgenic wheat enhances resistance to Fusarium head blight. Plant cell reports., 26, 479-488.

Martinelli, J. A., Chaves, M. S., Graichen, F. A. S., Federizzi, L. C., \& Dresch, L. F. (2014). Impact of Fusarium head blight in reducing the weight of oat grains. Journal of Agricultural Science, 6(5), 188.

Mesterházy, A. (1995). Types and components of resistance to Fusarium head blight of wheat. Plant Breeding, 114(5), 377386.

Mesterhazy, A., Bartok, T., Mirocha, C. G., \& Komorozy, R. (1999). Nature of wheat resistance to Fusarium head blight and role of Deoxynivalenol for breeding. Plant Breeding, $118(2), 7-110$.

Mesterházy, Á. (2002). Role of Deoxynivalenol in Aggressiveness of Fusarium graminearum and F. culmorum and in Resistance to Fusarium Head Blight. European Journal of Plant Pathology, 108, 675-684. https://doi.org/10.1023 /A:1020631114063.

Miller, J. D., Young, J. C., \& Sampson, D. R. (1985). Deoxynivalenol and Fusarium head blight resistance in spring cereals. Journal of Phytopathology, 113(4), 359-367.

Nganje, W. E., Kaitibie, S., Wilson, W. W., Leistritz, F. L., \& Bangsund, D. A. (2004). Economic impacts of Fusarium head blight in wheat and barley: 1993-2001. Agribusiness and applied economics rep. No. 528. Online. U.S. wheat and barley scab initiative. http://ageconsearch.umn. edu/bitsream/23627/1/aer538.pdf.

Nelson, P.E., Toussoun, T.A., Marasas, W.F.O. (1983). Fusarium species: An illustrated manual for identification. The Pennsylvania State University press University Park PA, 193.

Ollier, M., Talle, V., Brisset, A., et al. (2020). QTL mapping and successful introgression of the spring wheat-derived QTL Fhb1 for Fusarium head blight resistance in three European triticale populations. Theoretical and Applied Genetics, 133, 457-477. https://doi.org/10.1007/s00122-019-03476-0.

Piepho, H. P., \& Möhring, J. (2006). Selection in cultivar trials-is it ignorable? Crop Science, 46, 192-201.

Piepho, H. P., Möhring, J., Schulz-Streeck, T., \& Ogutu, J. O. (2012). A stage-wise approach for the analysis of multienvironment trials. Biometrical Journal, 54, 844-860.

Rutkoski, J., Benson, J., Jia, Y., Brown-Guedira, G., Jannick, J.L., \& Sorrells, M. (2012). Evaluation of genomic prediction methods for Fusarium head blight resistance in wheat. The Plant Genome, 5(2), 51-61.

Schisler, D.A., Khan, N.I., Boehm, M.J, \& Slininger, P. J., (2002). Greenhouse and Field Evaluation of Biological Control of Fusarium Head Blight on Durum Wheat. Papers in Plant Pathology, 393.

Schroeder, H. W., \& Christensen, J. J. (1963). Factors affecting resistance of wheat to scab caused by Gibberella zeae. Phytopathology, 53(7, 1), 831-838.

Searle, S. R. (1987). Linear models for unbalanced data. New York: John Wiley \& Sons.

Skinnes, H., Semagn, K., Tarkegne, Y., Maroy, A. G., \& Bjornstad, A. (2010). The inheritance of anther extrusion in hexaploid wheat and its relationship to Fusarium head blight resistance and deoxynivalenol content. Plant Breeding, 129(2), 149-155.

Tekauz, A., McCallum, B., Ames, N., \& Fetch, J. M. (2004). Fusarium head blight of oat - current status in western 
Canada. Canadian Journal of Plant Pathology, 26(4), 473479.

Tekle, S. (2014). Fusarium infection and its effects on germination and deoxynivalenol content of oats and screening for resistance by VIS-NIR spectroscopic methods. Dissertation: Norwegian university of life sciences.

Tekle, S., Skinnes, H., \& Bjørnstad, Å. (2013). The germination problem of oat seed lots affected by Fusarium head blight. European Journal of Plant Pathology, 135(1), 147-158.

Tekle, S., Dill-Macky, R., Skinnes, H., Tronsmo, A., \& Bjørnstad, $\AA$. (2012). Infection process of Fusarium graminearum in oats (Avena sativa L.). European Journal of Plant Pathology, 132(3), 431-442.

Tekle, S., Måge, I., Segtnan, V., \& Bjørnstad, Å. (2015). Nearinfrared Hyperspectral imaging of Fusarium-damaged oats (Avena sativa L.). Cereal Chemistry, 92(1), 73-80.

Tekle, S., Lillemo, M., Skinnes, H., Reitan, L., Buraas, T., \& Bjørnstad, A. (2018). Screening of oat accessions for Fusarium head blight resistance using spawn-inoculated field experiments. Crop Science, https://doi.org, 58, 143-151. https://doi.org/10.2135/cropsci2017.04.0264.
Xu, X. M., Nicholson, P., Thomsett, M. A., Simpson, D., Cooke, B. M., Doohan, F. M., Brennan, J., Monaghan, S., Moretti, A., Mule, G., Hornok, L., Beki, E., Tatnell, J., Ritieni, A., \& Edwards, S. G. (2008). Relationship between the fungal complex causing Fusarium head blight of wheat and environmental conditions. Phytopathology, 98(1), 69-78.

Xue, A., Chen, Y., Marchand, G., Guo, W., Ren, C., Savard, M., \& McElroy, A. R. B. (2015). Timing of inoculation and Fusarium species affect the severity of Fusarium head blight on oat. Canadian Journal of Plant Science, 95(3), 517-524.

Yan, W., Fregeau-Reid, J., Rioux, S., Pageau, D., Xue, A., Martin, R., Fedak, G., de Haan, B., Lajeunesse, J., \& Savard, M. (2010). Response of oat genotypes to Fusarium head blight in eastern Canada. Crop Science, 50, 134-142.

Yli-Mattila, T., Rämö, S., Hussien, T., Rauvola, M., Hietaniemi, V., \& Kaitaranta, J. (2017). Different grain grinding methods affect detection of Fusarium graminearum DNA and mycotoxins. Phytopathologia Mediterranea. https://doi. org/10.14601/Phytopathol Mediterr-20293.

Zadoks, J. C., Chang, T. T., \& Konzak, C. F. (1974). A decimal code for the growth stages of cereals. Weed Research, 14, 415-421. 